\title{
Note ON Title, TeXts, TRANSLITERATIONS, AND TRANSLATIONS
}

I have struggled with the title of this book. While I frequently considered changing the gendered "Man" for its exclusionary nature, I decided to leave it to reflect the first word and theme of this epic (andra, "man") and to acknowledge that the Odyssey is both a product and a producer of gendered discourse. I do believe, however, that the epic's core reflections about human psychology have universal application. Where the ancient contexts' own prejudices and structures complicate this, we find the most work left to do (as I explore in Chapters 6 and 7).

The Homeric poems are quoted from T. W. Allen's OCT edition of the Iliad (1931) and P. Von der Mühll's Teubner Odyssey (1962), respectively; Hesiod are from M. L. West's Theogony (1966), F. Solmsen's Works and Days (1970), and R. Merkelbach's and M. L. West's Fragmenta Hesiodea (1967). The text of the Scholia to Homer comes from Erbse (1969) and Dindorf (1855), except in the case where volumes from Pontani $(2007,2013)$ are available. All other Greek texts are drawn from the Thesaurus Linguae Graecae. Unless otherwise stated translations are my own, for which I have generally opted for usefulness over elegance. In transliterating proper names I used a hybrid system, preferring Latinized forms for names that are widely familiar but a more precise transliteration of the Greek for those less so: so, for example, Achilles and Oedipus (rather than Akhilleus and Oidipous), but Kyknos and The Ehoiai (rather than Cycnus and The Ehoeae). I ask for the reader's forbearance for any irregularities in this system (e.g., Herakles). 
